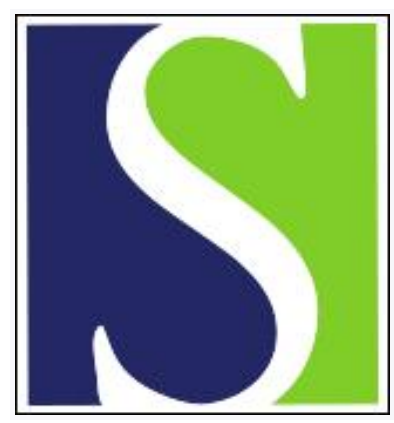

Scand J Work Environ Health 2020;46(1):69-76

https://doi.org/10.5271/sjweh.3841

Published online: 06 Aug 2019, Issue date: 01 Jan 2020

\title{
Sedentary work and risk of venous thromboembolism
}

by Johannesen CDL, Flachs EM, Ebbehøj NE, Marott JL, Jensen GB, Nordestgaard BG, Schnohr P, Bonde JPE

Previous studies have indicated an association between sedentary behavior and risk of venous thromboembolism (VTE). This cohort study comprising 78936 participants found no association between sedentary work defined by occupational sitting $\geq 6.5$ hours/day and the risk of VTE. Whether certain occupations with particularly high exposure to immobilized sitting positions are associated with VTE is not addressed in this study.

Affiliation: Camilla Ditlev Lindhardt Johannesen, Department of Occupational and Environmental Medicine, Frederiksberg and Bispebjerg Hospital, Bispebjerg Bakke 23, DK-2400 Copenhagen NV, Denmark. cjoh0108@regionh.dk

Key terms: occupational exposure; occupational exposure; sedentary; sedentary work; thromboembolism; thrombosis; venous thromboembolism; VTE

This article in PubMed: www.ncbi.nlm.nih.gov/pubmed/31385593

\section{Additional material}

Please note that there is additional material available belonging to this article on the Scandinavian Journal of Work, Environment \& Health -website. 


\title{
Sedentary work and risk of venous thromboembolism
}

\author{
by Camilla Ditlev Lindhardt Johannesen, MSc, ${ }^{1}$ Esben Meulengracht Flachs, PhD, ${ }^{1}$ Niels E Ebbehøj, DMSc, ${ }^{1}$ Jacob Louis \\ Marott, MSc, ${ }^{2}$ Gorm Boje Jensen, DMSc, ${ }^{2}$ Børge G Nordestgaard, DMSc, ${ }^{3,4}$ Peter Schnohr, DMSc, ${ }^{2}$ Jens Peter E Bonde, PhD 1,4
}

\begin{abstract}
Johannesen CDL, Flachs EM, Ebbehøj NE, Marott JL, Jensen GB, Nordestgaard BG, Schnohr P, Bonde JPE. Sedentary work and risk of venous thromboembolism. Scand J Work Environ Health. 2019;46(1): 69-76. doi:10.5271/sjweh.3841
\end{abstract}

Objective Prolonged seated immobility during long-distance flights is related to an increased risk of venous thromboembolism (VTE), but little, if anything, is known about the risk related to sedentary work. The objective of this paper was to examine the risk of VTE according to sitting posture at work.

Methods This prospective study includes a total of 78936 participants from the Copenhagen City Heart Study and the Copenhagen General Population Study, all without previous thromboembolic events and aged $<65$ years. An assessment of the number of hours spent in sitting position at work was assigned each participant at baseline using a job exposure matrix. VTE was identified through national patient registries. Survival analyses were performed to determine the risk of VTE according to sedentary position at work with adjustment for a range of known determinants including lifestyle and coagulation factors.

Results During the follow-up period of 582411 person years (mean follow-up, 7.4 years) 911 participants experienced their first VTE event. Multivariable adjusted analyses showed no difference in risk of VTE between occupational sitting $\geq 6.5$ hours/day and occupational sitting $\leq 3.5$ hours/day (hazard ratio $1.11,95 \%$ confidence interval 0.92-1.34).

Conclusion This study does not support the hypothesis that sedentary work is a risk factor for VTE in the general population. Whether certain occupations with particularly high exposure to immobilized sitting positions are associated with thromboembolic events is not addressed.

Key terms occupational exposure; thrombosis; VTE.

Venous thrombosis is the formation of a blood clot in one of the deep veins, usually in the lower limbs. If detached an embolus is transported in the veins and may become lodged in the lungs. Venous thromboembolism (VTE), comprising deep vein thrombosis and pulmonary embolism, is reported with an incidence of about 1.5 per 1000 individuals per year in high-income countries (1).

VTE has a multifactorial pathogenesis encompassing both inherited and acquired conditions, eg, prolonged immobility, including surgery and hospitalization, malignancy, obesity, hormone therapy, oral contraception and Factor V Leiden gene mutation (2-8). Virchow's triad describes three main causes of deep vein thrombosis: changes in blood flow, alterations in blood viscosity, and abnormalities in the vessel wall
$(9,10)$. Prolonged standing is thought to increase risk of venous insufficiency, which can cause leg oedema, heaviness, and dermatitis. Prolonged sitting may cause vein compression, which reduces blood flow and thereby increases the risk of VTE.

Seated immobility thromboembolism is a term used for all occurrences of VTE related to prolonged seated immobility during travel, work and recreation. A wellknown risk factor to seated immobility thromboembolism is long-distance air travel (10-12), while a possible association to prolonged immobility related to work and computer use has been studied to a lesser extent. Initially an association was recognized in a number of case reports and a case series (13-18). Since, three New Zealand case-control studies have reported one

1 Department of Occupational and Environmental Medicine, Bispebjerg and Frederiksberg Hospital, Denmark.

2 Copenhagen City Heart Study, Frederiksberg University Hospital, Denmark.

3 Department of Clinical Biochemistry and the Copenhagen General Population Study, Herlev and Gentofte Hospital, Denmark.

4 Faculty of Health and Medical Sciences, University of Copenhagen, Denmark.

Correspondence to: Camilla Ditlev Lindhardt Johannesen, Department of Occupational and Environmental Medicine, Frederiksberg and Bispebjerg Hospital, Bispebjerg Bakke 23, DK-2400 Copenhagen NV, Denmark. [E-mail: cjoh0108@regionh.dk] 
significant multivariate odds ratio (OR) for VTE of 2.8 [95\% confidence interval (CI) 1.2-6.1], but insignificant multivariate OR for VTE in both the first and the latest study (19-21). All three studies reported an increased risk of VTE by $8-10 \%$ per hour longer sitting. The two latest of these studies considered occupational groups as well and found no association in the multivariate analyses $(20,21)$. A Polish study has found computer use to be a predictor of seated immobility thromboembolism and an American study has found a positive association between TV viewing and VTE risk $(22,23)$. A Danish register-based cohort study found that sedentary workers, defined by different driver occupations, have a higher risk of VTE than workers with dynamic exertion at work, with a relative risk of 1.13 (95\% CI 0.99-1.29) (24).

Considering these findings and the overall frequency of sedentary occupations, the objective of this paper is to examine if sedentary occupational activity increases the risk of VTE compared to non-sedentary occupational activity while taking advantage of the strengths of this study compared to earlier studies. These strengths comprise the study size, the long follow-up time and the large range of potential confounding factors including individual risk factors.

\section{Methods}

\section{The study population}

The present study used data from two Danish prospective cohort studies: the Copenhagen City Heart Study and the Copenhagen General Population Study. Participants invited to the studies were aged $\geq 20$ years and randomly selected from the national Danish Civil Registration System $(7,25)$. The Copenhagen City Heart Study was initiated in 1976-1978, with follow-up examinations in 1981-1983, 1991-1994, and 2001-2003, each of which invited new participants to further supplement the cohort. The Copenhagen General Population study was initiated in 2003 with ongoing enrolment. Both studies obtained data from self-administered questionnaires, reviewed by an examiner, physical examinations, and blood samples.

Participants with a VTE diagnose prior to examination date were excluded together with participants aged $\geq 65$ years as this is the standard retirement age in Denmark (figure 1). Eligible participants were followed from 1 January 1977 or the date of entry into the study, whichever came latest, until one of the following occurred: first VTE event, death, emigration, age 65 or end of follow-up (31 December 2015).

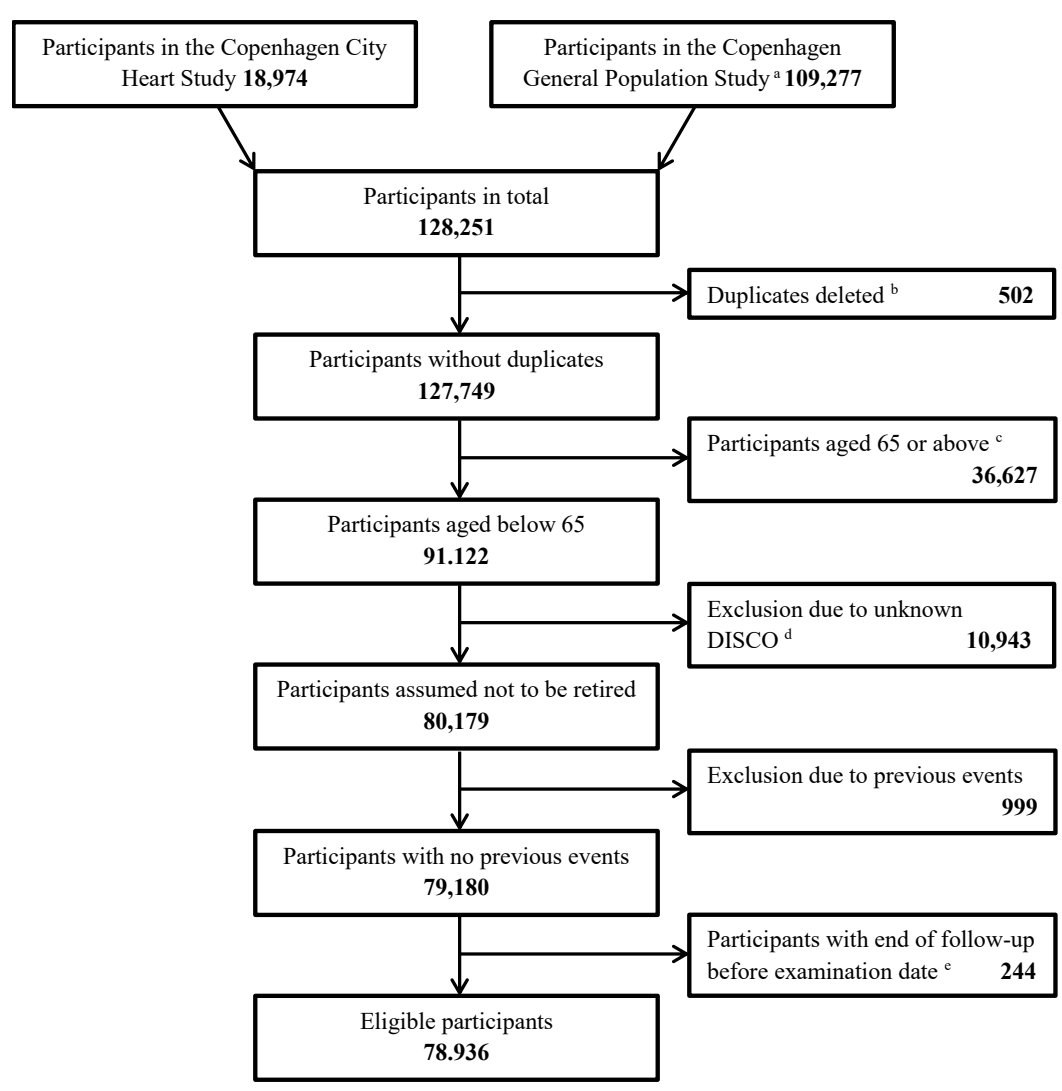

Figure 1.Flowdiagram for eligibleparticipants from the Copenhagen City Heart Study and the Copenhagen General Population Study, Denmark, 1977-2015. a Only participants completing a questionnaire are included. ${ }^{b}$ Results from the first examination date are kept. c The upper age limit of 65 years is chosen as this is the standard retirement age in Denmark. ${ }^{\mathrm{d}}$ The Danish version of the Standard Classification of Occupations. ${ }^{e}$ End of follow-up due to either emigration or end of study follow-up on 31 December 2015. 


\section{Venous thromboembolic events}

Information on deep vein thrombosis and pulmonary embolism diagnoses were obtained from the National Patient Registry, containing information on all in and out patient contacts in Denmark from 1 January 1977 until 9 March 2017, and the Danish Register of Causes of Death, containing information on all deaths in Denmark from 1 January 1977 until 31 December 2015. International Classification of Disease (ICD) codes were used to identify events, ICD-8 codes classifying diagnoses in the time period 1977-1993 and ICD-10 codes from of 1 January 1994 (ICD-8 codes 451.00, 451.08-09, 451.90, 451.92, 671.01-03 and 671.08-09 for deep vein thrombosis and 450.99 and 673.99 for pulmonary embolism; ICD-10 codes I80.1-3, O22.3 and O87.1 for deep vein thrombosis and I26.0, I26.9 and O88.2 for pulmonary embolism).

\section{Occupational sitting}

We constructed a job exposure matrix (JEM) linking occupational sitting hours to the Danish version of Standard Classification of Occupations (DISCO) using data from the Danish Work Environmental Cohort Study (26). The Danish Work Environmental Cohort Study systematically maps health and working conditions among Danish employees and takes place every fifth year (since 1990) and comprising information on $>10000$ adults in Denmark. Through questionnaires occupational sitting was measured by the question "Does your job involve sitting?" and the following six response categories: almost all the time, approximately $3 / 4$ of the time, approximately $1 / 2$ of the time, approximately $1 / 4$ of the time, rarely, and never. As a standard Danish working day is 8 hours, this was converted into the corresponding values: $8,6,4,2$, and 0 hours. The JEM was defined as the mean of self-reported occupational sitting hours within every DISCO code and linked to the study population. A categorical variable was then created dividing occupational sitting hours in three with the following cut-offs: $\geq 6.5,3.5-6.5$, and $\leq 3.5$ hours, the first category representing sedentary work.

\section{Covariates}

Information on age and sex was obtained from the social security number. The self-registered questionnaire provided baseline information on smoking status (divided into never, former, and current smokers), alcohol intake (daily, weekly, monthly, or never), leisure time activity level per week ( $<2$ hours exercise, 2-4 hours light exercise, 2-4 hours demanding exercise or $>4$ hours exercise), education ( $\leq 9$ years for elementary, 10-12 years for high school, or $>12$ years for academic), use of hormones (oral contraception and oestrogens) and menopause (yes/no). At the physical examinations height $(\mathrm{m})$, weight $(\mathrm{kg})$ and systolic/diastolic blood pressure $(\mathrm{mmHg})$ was measured (25). Body mass index (BMI) was calculated as weight (in $\mathrm{kg}$ ) divided by height (in meters) squared. Biochemical analysis of blood samples provided data on blood concentrations of the following constituents considered of interest for this study: total cholesterol, HDL cholesterol, LDL cholesterol, triglycerides, glucose, C-reactive protein, erythrocyte volume fraction, thrombocytes, coagulation factors $\mathrm{II}+\mathrm{VII}+\mathrm{X}$, fibrinogen, complement $\mathrm{C} 3$, and Factor V Leiden $(8,27,28)$. Information on cancer, cardiovascular disease, major surgery, and births was collected from the National Patient Registry.

\section{Statistical analyses}

Throughout analyses, data from the first examination the participants attended was used and the continuous variables systolic and diastolic blood pressures, BMI and blood concentrations were divided into tertiles (table 1 and supplementary tables S1-2, www.sjweh.fi/ show_abstract.php?abstract_id=3841). Time-dependent risk factors include three binary $(0 / 1)$ variables; one taking the value 1 within one year before or after the onset of any cancer, another takes the value 1 within three months before any major surgery and the third takes the value 1 nine months before or 3 months after giving birth (table 1). A categorical variable, divided into decades, was created on basis of examination date to adjust for calendar time.

Cox proportional hazards models were fitted, allowing for time varying covariates, with age as time scale. Results were reported as hazard ratios (HR) with 95\% CIs and throughout analyses the group of less occupational sitting ( $\leq 3.5$ hours) was used as reference. Some of the well-established risk factors for VTE were selected a priori to an initial multivariate model including age, sex, smoking status, education, use of hormones, BMI, cancer, cardiovascular disease, births, and major surgery. With respect to the initial model remaining covariates, except Factor V Leiden, were tested stepwise, including only those with a statistical significance level $\leq 0.01$ in the final model. A priori defined interaction terms were added to the final model to test for interactions between occupational sitting and leisure time activity level, BMI, sex, and age, respectively.

To ensure correct assumptions to the final model several sensitivity analyses were carried out, including Factor V Leiden, genotyped in 55\% of the population, analysis on imputed data and starting the risk time at the age of 50 years as it is expected that most events will occur at older ages.

Imputation on missing values was performed by Markov chain Monte Carlo method with all variables 
Table 1. Baseline characteristics for participants in the Copenhagen City Heart Study and the Copenhagen General Population Study, Denmark, 1977-2015.

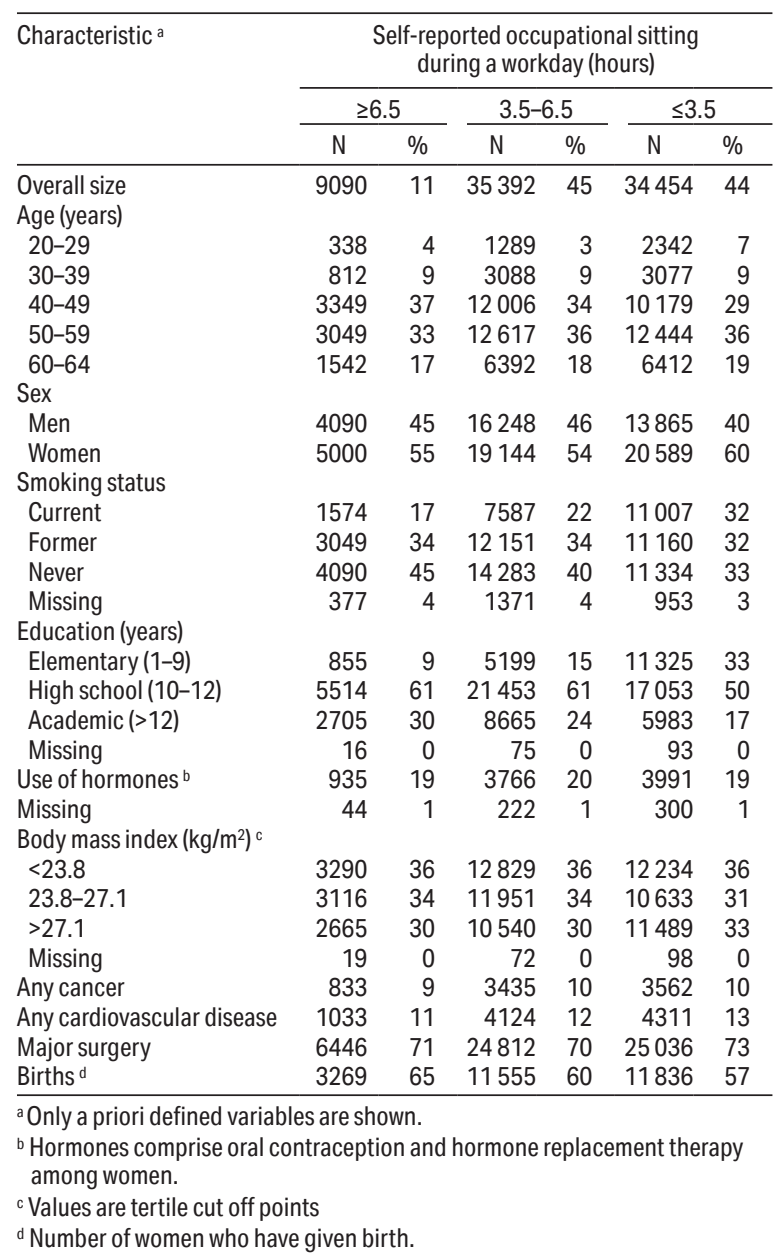

of the final models as predictors.

All statistical analyses were performed in SAS 9.4 statistical software (SAS Institute, Cary, NC, USA).

\section{Results}

A total of 78936 eligible participants were included in the study. Of these, 897 (1\%) were drivers, 24577 (31\%) were sitting $\geq 6.0$ hours equaling $3 / 4$ of the workday, and $9090(11 \%)$ were categorized in occupational sitting $\geq 6.5$ hours (table 1). The follow-up period was 582411 person years in total (mean follow-up, 7.4 years) and $79 \%$ of the participants had $\leq 10$ years of follow-up. During this time, 911 participants experienced their first venous thromboembolic event with an average age of 48.3 years (table 2). Complete case data consists of 60120 (76\%) participants, blood samples account for $80 \%$ of the missing data and smoking status $14 \%$. Well-
Table 2. End of follow-up description and follow-up time for participants in the Copenhagen City Heart Study and the Copenhagen General Population Study, Denmark, 1977-2015. [VTE=venous thromboembolism].

\begin{tabular}{|c|c|c|c|c|c|c|c|c|}
\hline & \multicolumn{8}{|c|}{$\begin{array}{c}\text { Self-reported occupational sitting } \\
\text { during a workday (hours) }\end{array}$} \\
\hline & \multicolumn{2}{|c|}{$\geq 6.5$} & \multicolumn{2}{|c|}{$3.5-6.5$} & \multicolumn{2}{|c|}{$\leq 3.5$} & \multicolumn{2}{|c|}{ Total } \\
\hline & $\mathrm{N}$ & $\%$ & $\mathrm{~N}$ & $\%$ & $\mathrm{~N}$ & $\%$ & $\mathrm{~N}$ & $\%$ \\
\hline First VTE event & 95 & 1 & 382 & 1 & 434 & 1 & 911 & 1 \\
\hline Deaths $^{\text {a }}$ & 151 & 2 & 770 & 2 & 1260 & 4 & 2181 & 3 \\
\hline Emigration & 58 & 1 & 187 & 1 & 157 & 0 & 402 & 1 \\
\hline Retirements ${ }^{b}$ & 2236 & 25 & 11233 & 32 & 12610 & 37 & 26079 & 33 \\
\hline Follow-up time ${ }^{c}$ & 58546 & 10 & 250122 & 43 & 273743 & 47 & 582411 & 100 \\
\hline
\end{tabular}

established risk factors were found to be associated to increased risk of thromboembolic events (figure 2).

\section{Venous thromboembolism and occupational sitting (complete case analyses)}

Univariate analyses showed a decreased risk of thromboembolic events in employees with sedentary work, but when adjusting for covariates no association was found (table 3). Multivariate analyses showed insignificant HR of 1.11 (95\% CI $0.92-1.34$ ) for occupational sitting $\geq 6.5$ hours/day and $0.94(0.83-1.07)$ for occupational sitting $3.5-6.5$ hours/day.

Within the group of high occupational sitting $(\geq 6.5$ hours), the three most frequent DISCO classifications are accounting, sales, and financing which represents 33\%.

\section{Interactions}

No significant interactions between occupational sitting and the covariates sex, age, BMI, and activity level in leisure time, respectively, were found.

\section{Sensitivity analyses}

When further adjusting for Factor $\mathrm{V}$ Leiden or changing retirement age from 65 to either 60 or 70 years results were consistent. Imputation of the missing data yielded a borderline insignificant HR of 1.16 (95\% CI 1.00-1.36) for occupational sitting $\geq 6.5$ hours (table 3 ), resembling primary results.

At least two examinations are available for $12 \%$ of the study population ( $\mathrm{N}=9766)$, and, of these, $10 \%$ changed category of occupational activity to less active, $9 \%$ changed to more active, and $81 \%$ remained in the same category of occupational activity. Inclusion of data from repeated examinations, thereby allowing participants to change level of occupational sitting and covariate status during the follow up period, resulted in a 


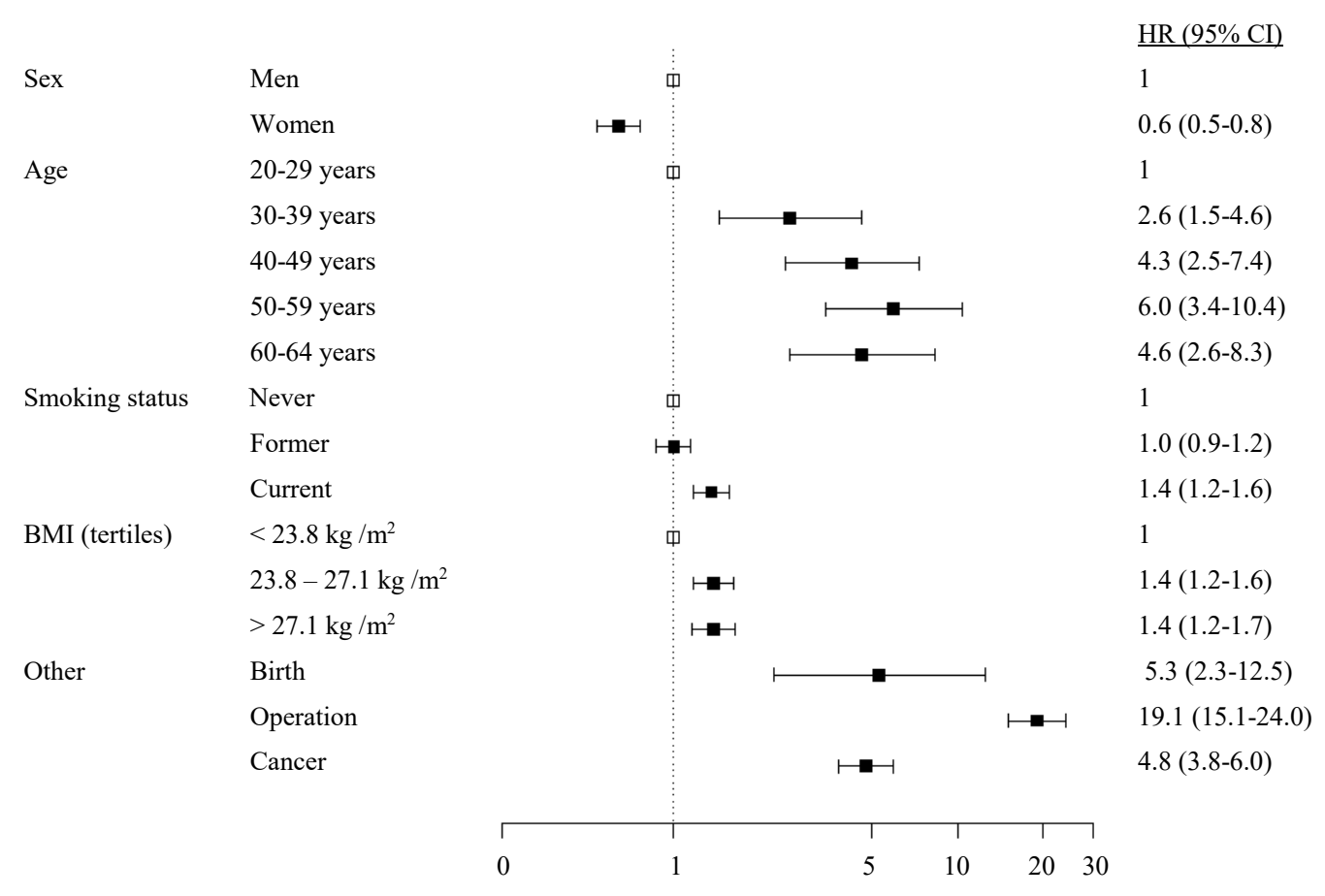

Figure 2. Risk of venous thromboembolism in well-established risk factors among participants in the Copenhagen City Heart Study and the Copenhagen General Population Study, Denmark, 1977-2015. [BMI=body mass index; Cl=confidence interval; HR=hazard ratio.]

HR of 1.21 (95\% CI 0.75-1.95) for occupational sitting $\geq 6.5$ hours, similar to the primary results.

Participants aged $\geq 50$ years account for 657 events (72\%) and 332296 (57\%) years of follow-up. Results from analyses on this subgroup yielded a HR of 1.07 (95\% CI $0.87-1.33$ ) for occupational sitting $\geq 6.5$ hours, consistent with primary results.

Table 3. Hazard ratios (HR) for venous thromboembolism according to occupational sitting hours among participants in the Copenhagen City Heart Study and the Copenhagen General Population Study, Denmark, 1977-2015. [Cl=confidence interval.]

\begin{tabular}{|c|c|c|c|c|c|}
\hline \multirow[t]{3}{*}{ Analysis } & \multicolumn{5}{|c|}{$\begin{array}{l}\text { Self-reported occupational sitting } \\
\text { during a workday (hours) }\end{array}$} \\
\hline & \multicolumn{2}{|c|}{$\geq 6.5$} & \multicolumn{2}{|c|}{$3.5-6.5$} & \multirow{2}{*}{$\begin{array}{c}\leq 3.5 \\
H R\end{array}$} \\
\hline & $\mathrm{HR}$ & $95 \% \mathrm{Cl}$ & $\mathrm{HR}$ & $95 \% \mathrm{Cl}$ & \\
\hline Univariate & 0.87 & $0.74-1.02$ & 0.81 & $0.74-0.89$ & 1.00 \\
\hline \multicolumn{6}{|l|}{ Multivariate } \\
\hline Chosen variables $^{a}$ & 1.08 & $0.92-1.27$ & 0.95 & $0.87-1.05$ & 1.00 \\
\hline Significant variables ${ }^{b}$ & 1.11 & $0.92-1.34$ & 0.94 & $0.83-1.07$ & 1.00 \\
\hline $\begin{array}{l}\text { Imputation on missing } \\
\text { values }\end{array}$ & 1.16 & $1.00-1.36$ & 1.04 & $0.95-1.14$ & 1.00 \\
\hline \multicolumn{6}{|c|}{$\begin{array}{l}\text { Chosen a priori defined variables are sex, age, smoking, education, use of } \\
\text { hormones, body mass index, cancer, cardiovascular disease, births, and } \\
\text { major surgery. }\end{array}$} \\
\hline \multicolumn{6}{|c|}{$\begin{array}{l}\text { b Variables included consist of chosen variables plus variables yielding a } \\
\mathrm{P}<0.01 \text { : alcohol, activity level in leisure time, menopause, blood cholesterol, } \\
\text { blood fibrinogen, blood coagulation factors }\|+\mathrm{V}\|+\mathrm{X} \text {, blood thrombocytes, } \\
\text { blood C-reactive protein, and blood complement C3. }\end{array}$} \\
\hline
\end{tabular}

\section{Discussion}

This study does not support the hypothesis that sedentary work is a risk factor for VTE in the general population.

This study found that $31 \%$ of the population sits more than $3 / 4$ of their workday, which is in line with previous findings (29). Several studies have indicated that prolonged immobility related to work and computer use is a risk factor for VTE, considering a minimum of 8 hours sitting during a day, whereas the present study has a cut-off at 6.5 hours sitting in the group of high occupational sitting and moreover did not account for immobilized sitting (19-22). It is possible that it is the quantity of prolonged sitting within a sedentary occupation, which increases the risk of VTE; as suggested by Healy et al (20) who found an increased risk of VTE for every hour longer sitting and for those who ate lunch at their desk (20).

When considering occupational groups Healy et al and Braithwaite et al found no association between occupations classified as sedentary and VTE (19-22). However, their classification put drivers into the less sedentary category, which is inconsistent with Suadicani et al (24) who found an increased risk of VTE in a sedentary occupational group based on drivers of various vehicles. This shows that the definition of a sedentary 
occupation might vary somewhat across studies. In the present study, no sub analyses on drivers were carried out as they represent $1 \%$ only of the study population. The three most frequent occupations in the high sedentary work group represent one third and are high-skilled white-collar workers, thus sedentary work represents a wide-range category of primarily office work, which might involve frequent interruptions, resulting in an attenuation of a possible association.

Blood samples representing the majority of missing data were added in the latest examination round, and thus not examined in participants only attending the first rounds of examination. Furthermore, the vast majority in these rounds are newly invited participants. Therefore, analyses of blood samples for fibrinogen, coagulation factors II $+\mathrm{VII}+\mathrm{X}$, thrombocytes, $\mathrm{C}$-reactive protein, blood complement $\mathrm{C} 3$, and Factor $\mathrm{V}$ Leiden are presumed to be missing at random (supplementary table S2). As results on imputed analysis resembles results from primary complete case analyses this presumption is validated.

The highest age group has a comparatively low HR (figure 2). Participants are invited to the examinations regardless of labor market participation, but those of the invited who participate might represent the healthier part, thus suggesting a healthy participant effect.

Information on traumas and long-term hospitalizations, representing possible confounders, is not available in the present study. By including major surgery, though, a part of these cases might be addressed.

\section{Strengths}

The size of the cohort is a major strength of the study. So is the prospective design in which data on occupational sitting was collected before onset of a VTE diagnosis, excluding participants with a VTE episode prior to start of follow-up. Contrary to earlier studies, it was possible to adjust for a large number of confounders. Significant increased risk of VTE found in covariates that are wellestablished risk factors for VTE supports the validity of the present study.

\section{Limitations}

Although the category of highest occupational sitting ( $\geq 6.5$ hours/day) only constitutes $11 \%$ of the study population, it might represent a too wide-range group of occupations, thereby reducing the feasibility to identify potential associations between some highly sedentary occupational groups, eg, drivers, and VTE

Using self-reported occupational sitting hours may potentially lead to misclassification bias, but when used in large population-based studies, an acceptable validity to this measure has been reported $(30,31)$.
VTE diagnoses in the National Danish Patient Registry have reported a positive predictive value of 0.59 (32). If random, this would not affect the results. However, the positive predictive value was found to be lower among women compared to men. This introduces a potential for misclassification bias as there is an uneven distribution of sex across categories of occupational sitting hours. For example, women representing a smaller part in the highest occupational sitting category $(\geq 6.5$ hours/day) than the less occupational sitting category ( $\leq 3.5$ hours/day), causing the positive predictive value to be lower for physically active work than sedentary work, may bias effect estimates towards the null.

The analyses were based on data from the first examination as follow-up examinations are only available for $12 \%$ of the participants and, therefore, do not consider any changes in occupational sitting over time. However, $81 \%$ in the subset of participants with at least two consecutive examinations remained in the same category of occupational sitting. Furthermore, as there are about ten years between consecutive examinations and $79 \%$ of the participants had a follow-up period of ten years or less, considering baseline data only most likely does not change the data for analyses in the greater part of the study population. In addition, results from the sensitivity analyses including activity level data from repeated examinations are similar to those for the primary results.

The study includes mainly Caucasians of European descent, recruited from the Metropolitan region in Denmark. All categories of occupational sitting are represented, and we are not to believe that risk profiles should change across the country. There is no data suggesting different outcomes in other populations.

\section{Concluding remarks}

The findings of this study indicate that there is no link between sedentary work and the risk of VTE when sedentary work is defined as occupational sitting $\geq 6.5$ hours/day. More studies should address the risk of VTE in selected highly immobilized occupations such as drivers.

\section{Ethics}

All participants in the Copenhagen City Heart Study and the Copenhagen General Population Study gave informed consent.

This study complies with the Declaration of Helsinki and was approved by Frederiksberg, Herlev and Gentofte Hospital and Danish ethics committees (ID of approval: H-KF-01-144/01). 


\section{Acknowledgement}

We thank staff and participants of the Copenhagen City Heart Study and the Copenhagen General Population Study for their contributions.

The study was funded by a scientific scholarship from Bispebjerg and Frederiksberg University Hospital. The Copenhagen City Heart Study is supported by the Danish Heart Association and The Metropolitan Region of Denmark.

\section{References}

1. Raskob GE, Angchaisuksiri P, Blanco AN, Buller H, Gallus A, Hunt BJ et al.; ISTH Steering Committee for World Thrombosis Day. Thrombosis: a major contributor to global disease burden. Arterioscler Thromb Vasc Biol 2014 Nov;34(11):2363-71. https://doi.org/10.1161/ ATVBAHA.114.304488.

2. Heit JA, Silverstein MD, Mohr DN, Petterson TM, O'Fallon WM, Melton LJ 3rd. Risk factors for deep vein thrombosis and pulmonary embolism: a population-based case-control study. Arch Intern Med 2000 Mar;160(6):809-15. https:// doi.org/10.1001/archinte.160.6.809.

3. Holst AG, Jensen G, Prescott E. Risk factors for venous thromboembolism: results from the Copenhagen City Heart Study. Circulation 2010 May;121(17):1896-903. https://doi. org/10.1161/CIRCULATIONAHA.109.921460.

4. Scarabin PY. Hormones and venous thromboembolism among postmenopausal women. Climacteric 2014 Dec;17 Suppl 2:34-7. https://doi.org/10.3109/13697137.2014.9567 17.

5. van Hylckama Vlieg A, Helmerhorst FM, Vandenbroucke JP, Doggen CJ, Rosendaal FR. The venous thrombotic risk of oral contraceptives, effects of oestrogen dose and progestogen type: results of the MEGA case-control study. BMJ 2009 Aug;339:b2921. https://doi.org/10.1136/bmj. b2921

6. Folsom AR, Cushman M, Tsai MY, Aleksic N, Heckbert SR, Boland LL et al. A prospective study of venous thromboembolism in relation to factor $\mathrm{V}$ Leiden and related factors. Blood 2002 Apr;99(8):2720-5. https://doi. org/10.1182/blood.V99.8.2720.

7. Klovaite J, Benn M, Nordestgaard BG. Obesity as a causal risk factor for deep venous thrombosis: a Mendelian randomization study. J Intern Med 2015 May;277(5):57384. https://doi.org/10.1111/joim.12299

8. Juul K, Tybjaerg-Hansen A, Schnohr P, Nordestgaard BG. Factor $\mathrm{V}$ Leiden and the risk for venous thromboembolism in the adult Danish population. Ann Intern Med 2004 Mar;140(5):330-7. https://doi.org/10.7326/0003-4819-1405-200403020-00008.

9. Rosendaal FR. Venous thrombosis: a multicausal disease. Lancet 1999 Apr;353(9159):1167-73. https://doi. org/10.1016/S0140-6736(98)10266-0.

10. Johnston RV, Hudson MF; Aerospace Medical Association Air Transport Medicine Committe. Travelers' thrombosis. Aviat Space Environ Med 2014 Feb;85(2):191-4. https://doi. org/10.3357/ASEM.3822.2014.

11. Cannegieter SC, Doggen CJ, van Houwelingen HC, Rosendaal FR. Travel-related venous thrombosis: results from a large population-based case control study (MEGA study). PLoS Med 2006 Aug;3(8):e307. https://doi. org/10.1371/journal.pmed.0030307.

12. Chandra D, Parisini E, Mozaffarian D. Meta-analysis: travel and risk for venous thromboembolism. Ann Intern Med 2009 Aug;151(3):180-90. https://doi.org/10.7326/00034819-151-3-200908040-00129.

13. Aldington S, Pritchard A, Perrin K, James K, Wijesinghe M, Beasley R. Prolonged seated immobility at work is a common risk factor for venous thromboembolism leading to hospital admission. Intern Med J 2008 Feb;38(2):133-5. https://doi.org/10.1111/j.1445-5994.2007.01597.x.

14. Beasley R, Heuser P, Raymond N. SIT (seated immobility thromboembolism) syndrome: a 21st century lifestyle hazard. N Z Med J 2005 Apr;118(1212):U1376.

15. Beasley R, Raymond N, Hill S, Nowitz M, Hughes R. eThrombosis: the 21 st century variant of venous thromboembolism associated with immobility. Eur Respir J 2003 Feb;21(2):374-6. https://doi.org/10.1183/09031936 .03 .00039403 .

16. Lee H. A new case of fatal pulmonary thromboembolism associated with prolonged sitting at computer in Korea. Yonsei Med J 2004 Apr;45(2):349-51. https://doi. org/10.3349/ymj.2004.45.2.349.

17. Ng SM, Khurana RM, Yeang HW, Hughes UM, Manning DJ. Is prolonged use of computer games a risk factor for deep venous thrombosis in children? Case study. Clin Med (Lond) 2003 Nov-Dec;3(6):593-4. https://doi.org/10.7861/ clinmedicine.3-6-593.

18. Braithwaite I, Shirtcliffe P, Jurevics R, Beasley R. Gaming: a 21 st century variant of seated immobility thromboembolism. N Z Med J 2018 Feb;131(1469):66-8.

19. West J, Perrin K, Aldington S, Weatherall M, Beasley R. A case-control study of seated immobility at work as a risk factor for venous thromboembolism. J R Soc Med 2008 May;101(5):237-43. https://doi.org/10.1258/ jrsm.2008.070366.

20. Healy B, Levin E, Perrin K, Weatherall M, Beasley R. Prolonged work- and computer-related seated immobility and risk of venous thromboembolism. J R Soc Med 2010 Nov;103(11):447-54. https://doi.org/10.1258/ jrsm.2010.100155.

21. Braithwaite I, Healy B, Cameron L, Weatherall M, Beasley $\mathrm{R}$. Venous thromboembolism risk associated with protracted work- and computer-related seated immobility: Acase-control study. JRSM Open 2016 Aug;7(8):2054270416632670. https://doi.org/10.1177/2054270416632670. 
22. Siniarski A, Wypasek E, Fijorek K, Gajos G, Undas A. Association between thrombophilia and seated immobility venous thromboembolism. Blood Coagul Fibrinolysis 2014 Mar;25(2):135-41. https://doi.org/10.1097/ MBC.0b013e3283648163.

23. Kubota Y, Cushman M, Zakai N, Rosamond WD, Folsom AR. TV viewing and incident venous thromboembolism: the Atherosclerotic Risk in Communities Study. J Thromb Thrombolysis 2018 Apr;45(3):353-9. https://doi. org/10.1007/s11239-018-1620-7.

24. Suadicani P, Hannerz H, Bach E, Gyntelberg F. Jobs encompassing prolonged sitting in cramped positions and risk of venous thromboembolism: cohort study. JRSM Short Rep 2012 Feb;3(2):8. https://doi.org/10.1258/ shorts.2011.011121.

25. Schnohr P, Jensen G, Lange P, Scharling H, Appleyard M. The Copenhagen City Heart Study: Østerbroundersøgelsen: tables with data from the third examination 1991-1994. Eur Heart J 2001;3(Suppl H):H1-H83.

26. Environment NRCftW [Internet]. Copenhagen: National Research Centre for the Working Environment; [Updated December 12th, 2010; Accessed September 3rd, 2018]. Available from: http://olddata.arbejdsmiljoforskning.dk/ Nationale\%20Data/NAK2005.aspx.

27. Nørgaard I, Nielsen SF, Nordestgaard BG. Complement C3 and High Risk of Venous Thromboembolism: 80517 Individuals from the Copenhagen General Population Study. Clin Chem 2016 Mar;62(3):525-34. https://doi.org/10.1373/ clinchem.2015.251314.
28. Klovaite J, Nordestgaard BG, Tybjærg-Hansen A, Benn M. Elevated fibrinogen levels are associated with risk of pulmonary embolism, but not with deep venous thrombosis. Am J Respir Crit Care Med 2013 Feb;187(3):286-93. https://doi.org/10.1164/rccm.201207-1232OC.

29. van der Ploeg HP, Møller SV, Hannerz H, van der Beek AJ, Holtermann A. Temporal changes in occupational sitting time in the Danish workforce and associations with all-cause mortality: results from the Danish work environment cohort study. Int J Behav Nutr Phys Act 2015 Jun;12:71. https://doi. org/10.1186/s12966-015-0233-1.

30. Clark BK, Thorp AA, Winkler EA, Gardiner PA, Healy GN, Owen $\mathrm{N}$ et al. Validity of self-reported measures of workplace sitting time and breaks in sitting time. Med Sci Sports Exer 2011 Oct;43(10):1907-12.

31. Reis JP, Dubose KD, Ainsworth BE, Macera CA, Yore MM. Reliability and validity of the occupational physical activity questionnaire. Med Sci Sports Exerc 2005 Dec;37(12):207583. https://doi.org/10.1249/01.mss.0000179103.20821.00.

32. Severinsen MT, Kristensen SR, Overvad K, Dethlefsen C, Tjønneland A, Johnsen SP. Venous thromboembolism discharge diagnoses in the Danish National Patient Registry should be used with caution. J Clin Epidemiol 2010 Feb;63(2):223-8. https://doi.org/10.1016/j. jclinepi.2009.03.018.

Received for publication: 29 October 2018 